\title{
Post-partum testosterone administration partially reverses the effects of perinatal cadmium exposure on sexual behavior in rats
}

\author{
Renato Couto-Moraes, Luciano Freitas Felício, Claudio Alvarenga de Oliveira and Maria Martha \\ Bernardi \\ Universidade de São Paulo, São Paulo, SP, Brazil
}

\begin{abstract}
This study investigated the effects of perinatal cadmium exposure on sexual behavior, organ weight, and testosterone levels in adult rats. We examined whether immediate postpartum testosterone administration is able to reverse the toxic effects of the metal. Forty pregnant Wistar rats were divided into three groups: 1) control, 2) $10 \mathrm{mg} \mathrm{kg}^{-1}$ cadmium chloride per day, and 3) 20 $\mathrm{mg} \mathrm{kg}^{-1}$ cadmium chloride per day. These dams were treated on gestational days 18 and 21 and from lactation 1 to 7 . Immediately after birth, half of the offspring from the experimental and control groups received $50 \mu$ (i.p.) of $0.2 \%$ testosterone. Male sexual behavior, histological analysis and weight of organs as well as serum testosterone levels were assessed. Results showed that both cadmium doses disrupted sexual behavior in male rats, and postnatal treatment with testosterone reversed the toxic effects of 10 $\mathrm{mg} \mathrm{kg}{ }^{-1}$ cadmium and attenuated the effects of $20 \mathrm{mg} \mathrm{kg}^{-1}$ cadmium. Body weight and absolute testis, epididymis, and seminal vesicle weight were decreased by the higher cadmium dose, and testosterone supplementation did not reverse these effects. Serum testosterone levels were unaffected by both cadmium doses. No histological changes were detected in all organs analyzed. Maternal cadmium exposure effects in sexual parameters of male rat offspring were explained by the altered masculinization of the hypothalamus. We suggest that cadmium damaged cerebral sexual differentiation by its actions as an endocrine disruptor and supported by the changes discretely observed from early life during sexual development to adult life, reflected by sexual behavior. Testosterone supplementation after birth reversed some crucial parameters directly related to sexual behavior.
\end{abstract}

Keywords: perinatal; testosterone; sexual behavior; cadmium; heavy metal

Received 30 Jul 2012; received in revised form 29 September 2012; accepted 18 October 2012. Available online 28 December 2012.

\section{Introduction}

The effects of cadmium as an endocrine disruptor have been well documented (Cheng et al., 2011; Takiguchi, 2006; Pollock \& Machin, 2008; Takiguchi \& Yoshihara, 2006; Zhang, Pang, Huang, Yan, \& Lin, 2008). Cadmium has potent estrogen- and androgen-like activity in vitro and in vivo by targeting estrogen and androgen receptors. Cadmium ${ }^{2+}$ was shown to inhibit progesterone synthesis in placental tissues (Kawai et al., 2002). Chronic cadmium exposure leads to a disruption of hypothalamic-pituitary-testicular axis activity in male rats (Lafuente \& Esquifino, 1998a; Lafuente, Gonzalez-

Luciano Freitas Felício, Renato Couto-Moraes, Department of Pathology, Claudio Alvarenga de Oliveira,Department of Animal Reproduction, School of Veterinary Medicine,University of São Paulo - USP, São Paulo, Brazil. Maria Martha Bernardi, Health Sciences Institute, Paulista University - UNIP,São Paulo, SP, Brazil. Correspondence regarding this article should be directed to: Maria Martha Bernardi, Universidade Paulista UNIP, Instituto de Cências da Saúde, Pró-Reitoria de Pesquisa e Pós-graduação, Rua Dr. Bacelar, 1212 - Vila Clementino, São Paulo, SP, Brazil- 04026-002, Phone: +55-11-5586-4000, Fax: +55-11-3091-7829. E-mail: marthabernardi@gmail.com
Carracedo, Cabaleiro, Romero, \& Esquifino, 2005b; Lafuente, Gonzalez-Carracedo, Romero, Cabaleiro, \& Esquifino, 2005a; Pillai \& Gupta, 2005) by acting at the hypothalamic level. Lafuente \& Esquifino (1998a) reported that cadmium exposure interfered with the onset of puberty by changing serum prolactin levels. Murthy, Saxena, Lal, \& Chandra (1989) found that cadmium decreased the secretion of hypothalamic monoamines, which are involved in sexual behavior. Studies from our laboratory conducted by Salvatori, Talassi, Salzgeber, Spinosa, \& Bernardi (2004) demonstrated that prenatal maternal cadmium exposure, particularly during the organogenesis period, damaged male and female sexual behavior by acting as an endocrine disruptor.

Steroid hormones play a significant role in the brain and neuroendocrine system both pre- and neonatally, resulting in gender dimorphism in the behavioral and metabolic aspects of reproduction in adulthood (Jacobson \& Gorski, 1981; MacLusky \& Naftolin, 1981). Brain sexual differentiation occurs during the perinatal period after an abrupt discharge of testicular testosterone in males. In male rats, testosterone surges markedly occur on days 18-19 of gestation (Ward \& Weisz, 1984) and 
again during the first few hours following parturition (Corbier, Kerdelhue, Picon, \& Roffi, 1978). Thus, early exposure to androgens from the developing testes results in masculinization and defeminization of the brain. The former entails permanent actions that support typical male copulatory behaviors and patterns of gonadotropin secretion. Testosterone per se is not responsible for masculinizing the brain (Roselli \& Klosterman, 1998). This process requires the conversion of androgen to estrogen, and the neural aromatization of androgens to estrogens is known to be a critical step in the development and adult expression of male sexual behavior in various species (Freeman \& Rissman, 1996; Lephart, 1996). During this period of brain sexual differentiation, testosterone or its metabolites are fundamental for the masculinization and defeminization of sexual behavior, establishment of gonadotropin secretion patterns, and various morphological indices. Alterations in the process of hypothalamic sexual differentiation, if present, are generally perceived only at puberty or during adult reproductive life (Gerardin, Bernardi, Moreira, \& Pereira, 2006; Piffer \& Pereira, 2004).

We previously examined whether immediate postpartum testosterone administration is able to reverse the toxic effects of perinatal cadmium treatment on physical and reflexologic development in rat pups (Couto-Moraes, Felicio, \& Bernardi, 2010). Testosterone administration was not able to reverse the effects of cadmium, even on those parameters more directly related to the androgenic system such as the descent of the testis and anogenital distance delays. The present study examined two aspects of cadmium exposure: 1) long-term effects of perinatal exposure to 10 and $20 \mathrm{mg} /$ $\mathrm{kg}$ cadmium on sexual aspects were examined, and 2) whether postnatal testosterone treatment can reverse the disruptive effects of cadmium on male sexual parameters. Thus, sexual behavior, serum testosterone levels, weight, and reproductive organ histology were evaluated.

\section{Materials and Methods Animals}

Adult male and female Wistar rats obtained from the Department of Pathology, School of Veterinary Medicine and University of São Paulo, Brazil and weighing approximately 310 and $230 \mathrm{~g}$, respectively, 100 and 75 days old, respectively, were used. The animals were housed in polypropylene cages $(40 \times 50 \times 20 \mathrm{~cm})$ under controlled temperature $\left(20 \pm 2^{\circ} \mathrm{C}\right)$ and humidity $(70 \pm 5 \%)$ with a $12 \mathrm{~h} / 12 \mathrm{~h} \mathrm{light} /$ dark cycle (lights on at 6:00 AM). Food (Nuvilab CR1, species-specific ration) and water (filtered in porcelain) were provided ad libitum throughout the study. All procedures were approved by the Animal Care Committee (protocol no. 435/2004-FMZ-USP) in accordance with the guidelines of the Committee on Care and Use of Laboratory Animal Resources, National Research Council (USA).

Nulliparous female rats ( 75 days) were manipulated daily by the investigators for 14 consecutive days to avoid stress interference on female rats estrus cycle (Lovick, 2012). After this time, female estrus was determined by vaginal cytology. Estrous rats were randomly divided into pairs and placed with one fertile male overnight. On the following morning, the success of mating was confirmed by the presence of spermatozoa in vaginal smears. This day was considered gestational day 0 (GD0). Two pregnant female rats were maintained in each cage until GD18, after which time they were isolated to build their nests.

\section{Drugs}

Cadmium chloride $\left(\mathrm{CdCl}_{2}\right.$, J. T. Baker) was diluted in distilled water at $1 \%$ and $2 \%$ concentrations and orally administered in a volume of $1 \mathrm{ml} \mathrm{kg} \mathrm{kg}^{-1}$ body weight, according to female body weight fluctuation. Cadmium doses were chosen based on previous studies of our group showing that maternal exposure to the higher dose used here promoted changes in offspring sexual sphere (Salvatori et al., 2004). Testosterone propionate (Sigma) diluted in almond oil (Lederc) to a concentration of $0.2 \%$ was administered i.p. in a $50-\mu l$ volume according to Gratan \& Selmanoff (1994). Nankeen black paint (Acrilex) was used to mark littermates.

\section{Formation of the experimental groups}

Forty dams were divided into three groups. Two experimental groups ( $n=16$ per group) were treated orally by gavage once daily with 10 or $20 \mathrm{mg} \mathrm{kg}^{-1}$ cadmium according to the following regimen: on GD18 and GD21 and daily from postnatal day 1 (PND1) to PND7. These treatment periods correspond to the male brain sexual differentiation in rats. The control group was treated with $0.9 \% \mathrm{NaCl}$ according to the same schedule $\left(1 \mathrm{ml} \mathrm{kg}^{-1}\right.$, gavage, $\left.n=8\right)$. Immediately after birth, half of the pups from the experimental groups received an i.p. injection of testosterone propionate, and the other half received almond oil under the same conditions as the control group. Thus, the following experimental groups were formed: SS - perinatal saline + saline solution in adult age $(n=8 /$ litter $)$, CDS10perinatal cadmium $10 \mathrm{mg} \mathrm{kg}^{-1}+$ saline solution in adult age $(n=8 /$ litter), CDT10 - perinatal cadmium $10 \mathrm{mg}$ $\mathrm{kg}^{-1}+$ testosterone in adult age $(n=8 /$ litter), CDS20perinatal cadmium $20 \mathrm{mg} \mathrm{kg}^{-1}+$ saline solution in adult age $(n=8 /$ litter), CDT20 - perinatal cadmium $20 \mathrm{mg}$ $\mathrm{kg}^{-1}+$ testosterone in adult age $(n=8 /$ litter $)$.

\section{Offspring studies}

Immediately after birth, all pups were examined externally for the presence of gross abnormalities. They were sexed and weighed, leaving a total of eight pups (four males and four females) with each dam until weaning on PND21. On this day, the littermates were separated, housed together by gender, and grouped under the same laboratory conditions as their parents. Three male pups of eight litters/treatment were marked on the right foreleg used to evaluate the sexual behavior, 


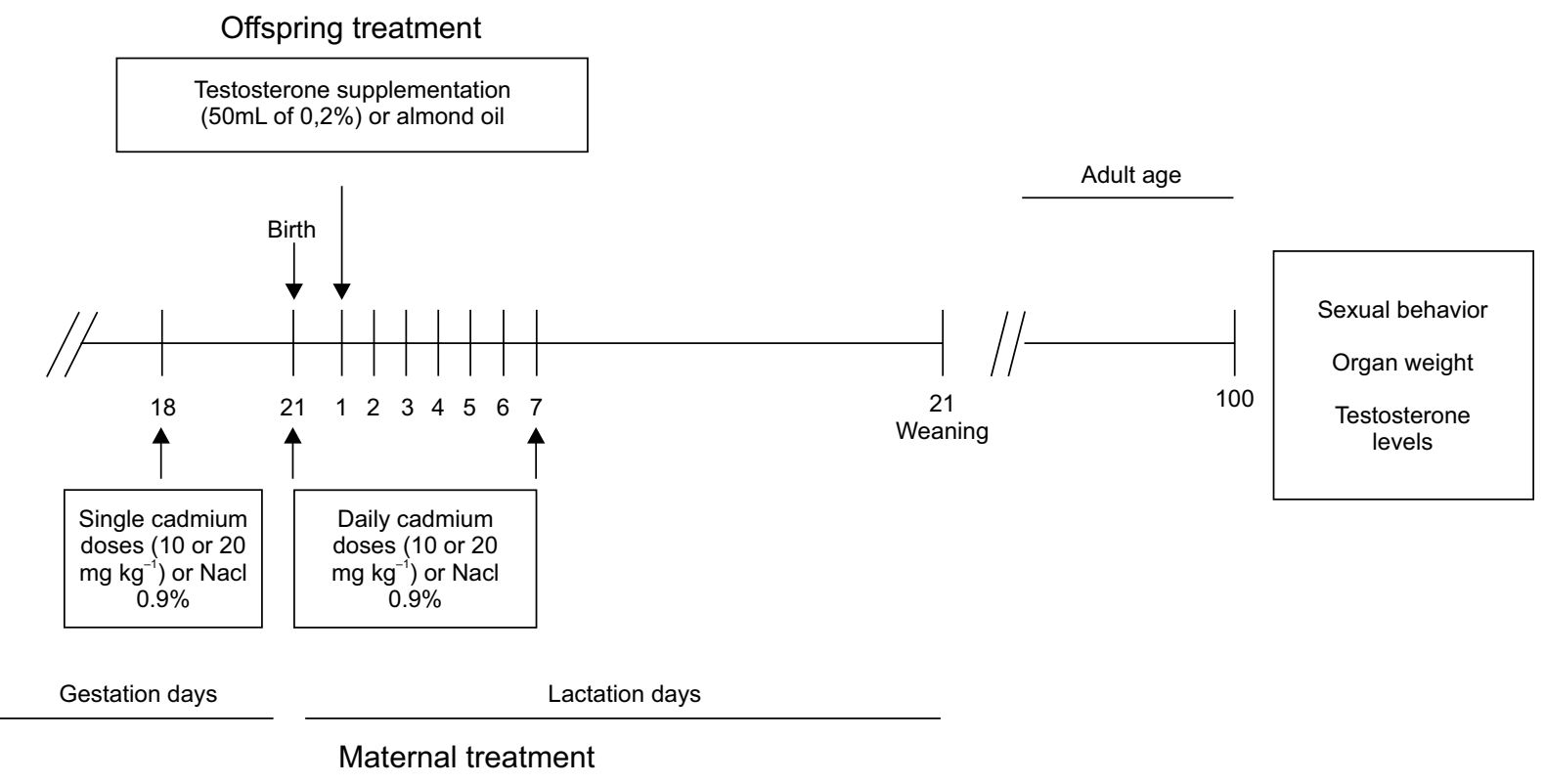

Figure 1. Diagram of experiments. Cadmium (10 and $\left.20 \mathrm{mg} \mathrm{kg}^{-1}\right)$ was administered to dams on gestational day 18 (GD18) and from GD21 to postnatal day 7 (PND7). The pups received testosterone supplementation ( $50 \mu 1$ of a $0.2 \%$ solution, i.p.) or almond oil immediately after birth. On PND100, sexual behavior, organ weight, and testosterone levels were evaluated.

body and organs weights, histological analysis and testosterone serum levels. The remaining male and female offspring were used in other experiments in our laboratory.

\section{Sexual behavior}

On PND100, sexual behavior in male rat offspring was evaluated according to Felicio, Palermo-Neto, \& Nasello (1989). The apparatus had the following characteristics: wood box painted gray $(56 \times 35 \times 31$ $\mathrm{cm}$ ), superior portion with mobile lid, and one front glass wall. Animals were maintained under controlled conditions on a partially reversed light/dark cycle (lights on at 10:00 PM and off at 10:00 AM) for at least 24 days before the test. All sexual behavior tests were held 4 to $8 \mathrm{~h}$ after the beginning of the dark period. To minimize the possible influence of circadian changes on sexual behavior, control and experimental animals were alternated. A layer of sawdust served as bedding and new sawdust and sawdust originating from self-house cages formed it. During all of the tests, two 40-W red lamps illuminated the test room.

For the observations, each male rat was individually placed in the box for $5 \mathrm{~min}$ before the mating test to adapt to the new environment. One sexually receptive female was then placed in the box, and the following parameters were measured for a period of $40 \mathrm{~min}$ : latency to first mount, latency to first intromission, latency to first ejaculation, number of mounts until first ejaculation, number of intromissions until first ejaculation, latency to post-ejaculatory mount, latency to post-ejaculatory intromission, and total number of ejaculations. The frequency of mounts per minute (quotient of ratio between the number of mounts until the first ejaculation and difference in time between the first ejaculation and first mount) and the frequency of intromissions per minute (quotient of ratio between the number of intromissions until the first ejaculation and difference in time between the first ejaculation and first intromission) were calculated.

\section{Body and organ weight and histological evaluation of reproductive organs}

On PND100, adult rats were weighed. After euthanasia by decapitation, the rats were carefully dissected, and the following reproductive organs were collected: testes, epididymis, seminal vesicle, and ventral prostate. These organs were then washed in saline solution and dried on hygienic paper. The measurement of organ weight was performed using a digital scale (Mettler). Finally, the organ fragments were collected and fixed with $10 \%$ phosphate-buffered formalin until histology was performed. Additionally, the absolute weights were calculated. For the histological evaluation, after fixation, the organ fragments were passed through the usual stages of paraffin inclusion. Paraffin-embedded tissues were then sectioned $(5 \mu \mathrm{m})$ and stained with hematoxylin and eosin (HE) for examination by light microscopy.

\section{Serum testosterone levels}

After euthanasia, trunk-blood samples were taken to measure testosterone levels. Serum testosterone in adult rats (on PND100) was measured using a solidphase radioimmunoassay and commercial kit (Coata-Count) purchased from Diagnostic Products (Los Angeles, CA, USA). One 50- $\mu 1$ aliquot of serum was dispensed into each assay tube, and then $1 \mathrm{ml}$ of buffer that contained the tracer $(40000 \mathrm{cpm} /$ tube $)$ was added. A standard curve was set with minimal concentrations 
of testosterone from $1.24 \mathrm{ng} / \mathrm{dl}$. The mixture was incubated for $3 \mathrm{~h}$ at $37^{\circ} \mathrm{C}$. The tubes were then decanted, and the radioactivity bound to the tube was measured in a gamma counter with a built-in computer, which calculated the final values of testosterone in $\mathrm{ng} / \mathrm{dl}$ serum. A single assay was performed. Intra-assay coefficient of variation ranged from $7.33 \%$ to $7.66 \%$, and inter-assay coefficient of variation was less than $3.7 \%$. The hormone assay was performed in the Laboratory of Hormonal Dosages, Department of Animal Reproduction, School of Veterinary Medicine, University of São Paulo.

\section{Statistical analysis}

One-way analysis of variance (ANOVA) followed by the Tukey multiple comparison test were used for data analysis. In all cases, $p<0.05$ was considered statistically significant. Statistical analyses were performed using Instat software, version 3.01 (GraphPad, San Diego, CA, USA).

\section{Results}

\section{Sexual behavior}

The mean latencies to first mount $\left(F_{4,35}=8.57\right.$, $p<0.0001)$ and first intromission $\left(F_{4,35}=9.28, p<\right.$ $0.0001)$ increased in pups perinatally exposed to $10 \mathrm{mg}$ $\mathrm{kg}^{-1}$ cadmium without testosterone supplementation. Testosterone supplementation reversed these effects of cadmium. Pups exposed to $20 \mathrm{mg} \mathrm{kg}^{-1}$ cadmium exhibited increased latencies to first mount and first intromission,
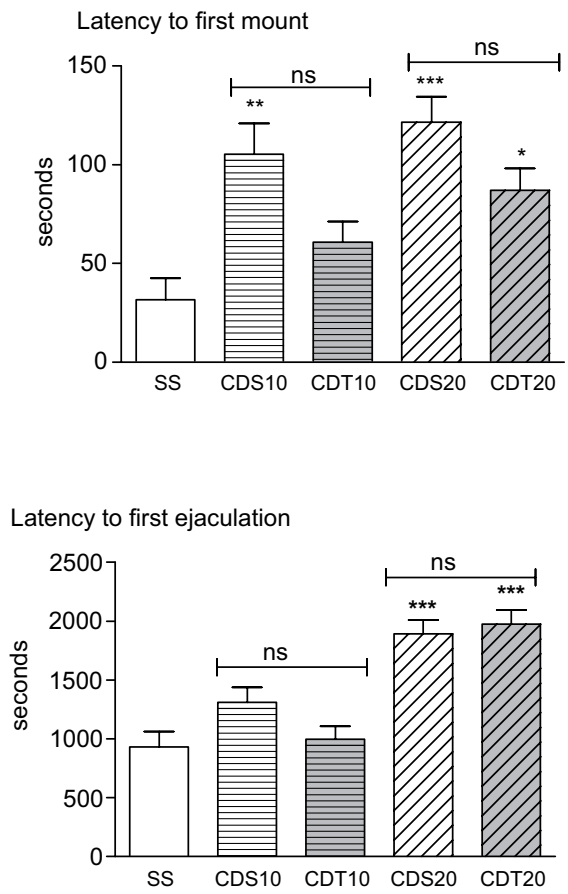

and testosterone supplementation attenuated these effects. The latency to first ejaculation increased $\left(F_{4,35}\right.$ $=14.23, p<0.0001)$ with exposure to the higher dose of cadmium. Testosterone supplementation did not reverse this effect. Compared with the control group, no effects of either cadmium treatment or testosterone supplementation were found on post-ejaculatory latency $\left(F_{4,35}=2.15, p=0.09\right.$; Figure 2$)$.

The number of mounts until first ejaculation $\left(F_{4,35}=\right.$ $2.97, p<0.03)$, number of intromissions until ejaculation $\left(F_{4,35}=0.51, p<0.0001\right)$, and number of ejaculations $\left(F_{4,35}=5.30, p<0.001\right)$ were different between groups (Figure 3). The Tukey multiple comparison test indicated that the number of intromissions until ejaculation and total number of mounts increased in pups perinatally exposed to the higher cadmium dose. Testosterone supplementation attenuated the perinatal effects of cadmium. The total number of ejaculations in $40 \mathrm{~min}$ $\left(F_{4,35}=8.57, p<0.0001\right)$ decreased in experimental pups perinatally exposed to the lower and higher doses of cadmium. In both cases, testosterone supplementation reversed the perinatal effects of cadmium.

With regard to sexual parameters (Table 1), the frequency of intromissions per minute was different between groups $\left(F_{4,25}=4.41, p=0.007\right)$. The post hoc test revealed an increase in this parameter in pups perinatally exposed to the higher dose of cadmium with testosterone supplementation compared with the control group. No significant differences were found between groups in the frequency of mounts per minute.

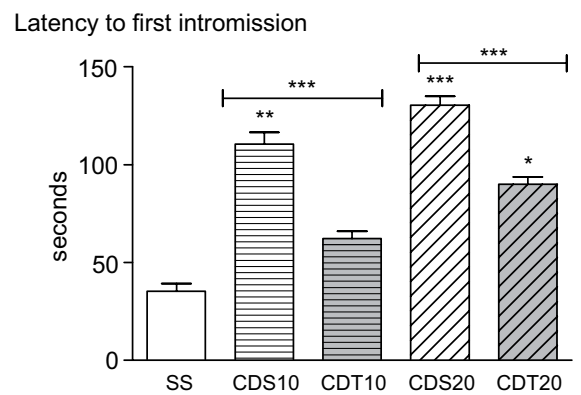

Latency to postejaculatory mount

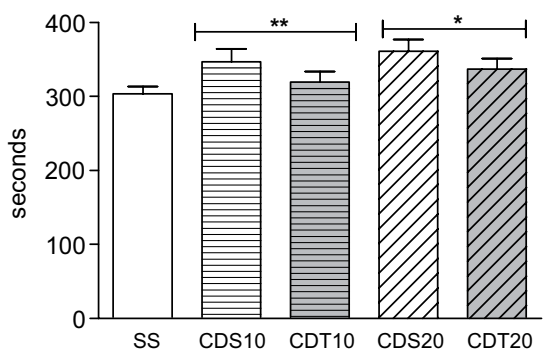

Figure 2. First mount, first intromission, first ejaculation, and post-ejaculatory mount latencies in male rats perinatally treated with cadmium that received or did not receive testosterone supplementation immediately after birth. SS group: maternal treatment with saline and the pups were treated with almond oil. CDS10 and CDS20 groups: maternal treatment with cadmium and the pups were treated with almond oil. CDT10 and CDT20 groups: maternal treatment with cadmium and the pups were treated with testosterone (one-way ANOVA followed by the Tukey multiple comparison test). ${ }^{*} p<0.05, * * p<0.01, * * * p<0.001$ compared with control group or between pairs. Differences between groups treated or not with testosterone are indicated by the bar on the groups. Data are expressed as mean $\pm \mathrm{SD} . n=8$ /groups. 

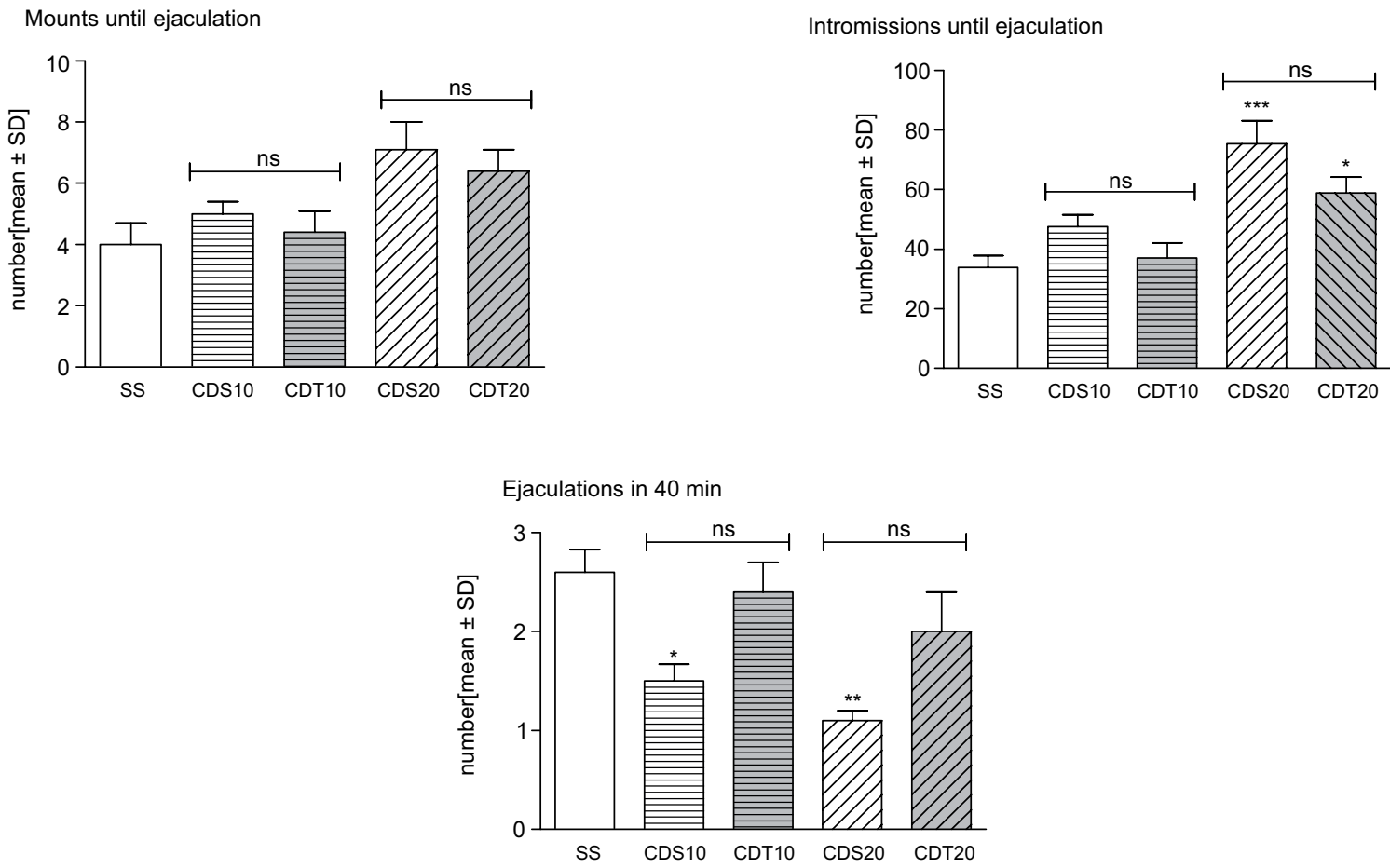

Figure 3. Mounts and intromissions until first ejaculation and number of ejaculations in adult male rats perinatally treated with cadmium that received or did not receive testosterone supplementation immediately after birth. See Figure 2 for group descriptions. $* p<0.05, * * p<0.01, * * * p<0.001$ compared with control group or between pairs (one way ANOVA followed by the Tukey multiple comparison test). Differences between groups treated or not with testosterone are indicated by the bar on the groups. Data are expressed as mean \pm SD. $n=8$ /groups.

Table 1. Effects of postnatal testosterone administration on sexual behavior indices in male rats perinatally exposed to cadmium or saline solution via gavage to the dams during the cerebral sexual differentiation period. The data are expressed as mean \pm SD. $n=8 /$ group

\begin{tabular}{lccccc}
\hline & SS & CDS10 & CDT10 & CDS20 & CDT20 \\
\hline Frequency of & 0.26 & 0.26 & 0.30 & 0.24 & 0.36 \\
mounts/minute & \pm 0.11 & \pm 0.05 & \pm 0.17 & \pm 0.07 & \pm 0.10 \\
& & & 2.41 & 2.56 & $3.38 * *$ \\
Frequency of intromissions/minute & 2.35 & 2.43 & \pm 0.69 & \pm 0.40 & \pm 0.47 \\
& \pm 0.48 & \pm 0.40 & & \\
& & & & & \\
\end{tabular}

See Fig. 2 legend for group descriptions. ${ }^{* *} p<0.01$, compared with $\mathrm{S}+\mathrm{S}$ group (one way ANOVA followed by Tukey multiple comparison test).

\section{Weight and histological evaluation of reproductive organs}

In adults, the absolute weights of the body $\left(F_{4,25}=\right.$ $25.05, p<0.0001)$, testes $\left(F_{4,25}=22.90, p<0.0001\right)$, epididymis $\left(F_{4.25}=164.30, p<0.0001\right)$, and seminal vesicle $\left(F_{4,25}=43.84, p<0.0001\right)$ were significantly different between groups. No differences were found in prostate weight $\left(F_{4,25}=1.75, p=0.16\right)$ or serum testosterone levels $\left(F_{4,45}=0.04, p=0.99\right)$ between groups (Figure 4).The Tukey multiple comparison test revealed that the weights of the body, testes, epidydimis, and seminal vesicle similarly decreased in the postnatally testosterone-treated and -untreated groups compared with the control group. Additionally, testosterone treatment in $10 \mathrm{mg} \mathrm{kg}^{-1}$ cadmium-exposed rats reversed the decrease in epidydimis weight. Histological evaluation of the reproductive organs did not reveal changes in the normal pattern of reproductive organs in experimental rats (data not shown).

\section{Discussion}

The present study found that perinatal cadmium exposure disrupted sexual behavior in male rats, and postnatal treatment with testosterone reversed or attenuated these effects. Descriptions of male sexual behavior in nonhuman animals have distinguished two separate phases: a highly variable sequence of behaviors that involves attracting and courting a female followed by a highly stereotyped copulatory sequence. This initial variable phase is often referred to as the appetitive phase, whereas the highly stereotyped copulatory phase is often referred to as the consummatory (motivational) phase. The consummatory (copulatory) aspects of male sexual behavior must be expressed in a coordinated manner to produce a functionally adapted behavioral sequence that can result in the fertilization of the female and successful reproduction (Balthazart \& Ball, 2007).

The method used here to analyze the sexual behavior of male offspring allowed us to distinguish between sexual 

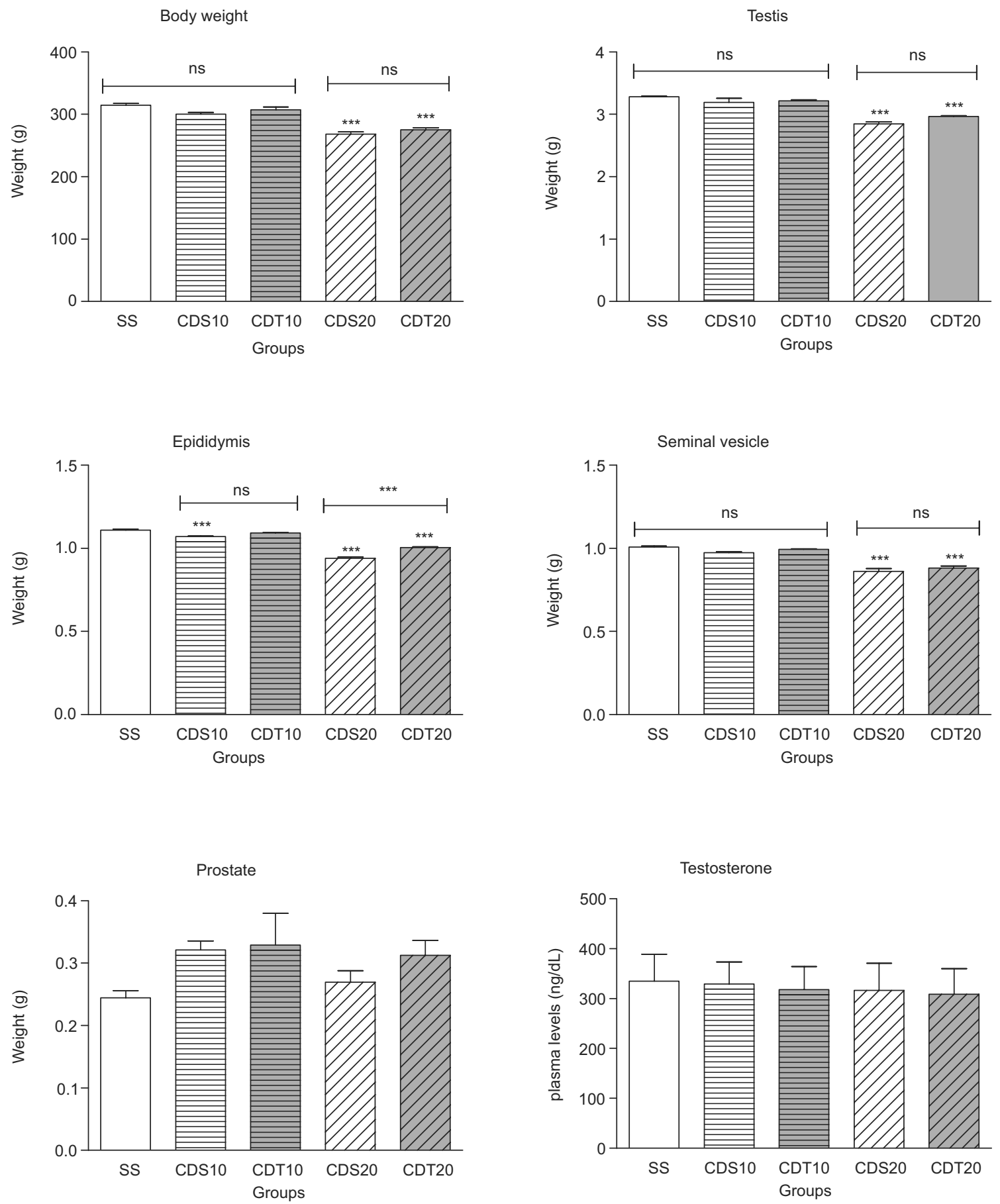

Figure 4. Absolute weights of the body, testes, epididymis, seminal vesicle, and prostate and testosterone levels in adult male rats perinatally treated with cadmium that received testosterone supplementation or almond oil immediately after birth. See Figure 2 for group descriptions. ${ }^{*} p<0.05,{ }^{*} p<0.01,{ }^{* *} p<0.001$ compared with control group or between pairs (one-way ANOVA followed by the Tukey multiple comparison test). Differences between groups treated or not with testosterone are indicated by the bar on the groups. $n=8$ /groups.

motivation (i.e., the ease with which sexual behavior is activated, or "libido") and the execution of the copulatory acts (i.e., performance or "potency" (Meisel \& Joppa, 1994). Mount latency is a measure of sexual motivation. The same is valid for intromission latency but, in this case, it requires penile erection and the coordinated activity of the striated penile muscles; therefore, it is not entirely determined by sexual motivation (Agmo, 1999). The number of mounts or intromissions reflects sexual motivation, but it may be confounded by other intervening factors and should be interpreted with caution (Agmo, 1997). Rats prenatally treated with cadmium showed a decreased number of total mounts and consequently a greater number of intromissions. Compared with the control group, rats prenatally treated with cadmium did not show significant differences in mount frequency, an index of motor activity, suggesting that the motor aspects of sexual behavior were not affected by prenatal treatment 
with the metal. Additionally, the increased latency to the first ejaculation and lower number of ejaculations appeared to reflect a decrease in sexual behavior potency. Thus, perinatal exposure to cadmium reduced both the motivational and performance aspects of male sexual behavior.

Cadmium binds to estrogen receptor- $\alpha$ (ER- $\alpha)$ and androgen receptors (ARs) and activates them (Martin et al., 2002; Stoica, Katzenellenbogen, \& Martin, 2000). Therefore, the steroidal endocrine-disrupting effect of cadmium (Piasek, Laskey, Kostial, \& Blanusa, 2002) could explain these results. This metal can interact with the estrogen nuclear receptor and trigger cellular mechanisms in estrogen-dependent processes in the central nervous system, particularly in the pituitary gland, in both the male and female reproductive systems (Sonnenschein \& Soto, 1998; Temple, Scordalakes, Bodo, Gustafsson, \& Rissman, 2003) showing that ER knockout mice exhibited a tendency toward an increase in serum testosterone levels during puberty, an increase in the numbers of complete and incomplete mounts, and an increase in ejaculation latency. Additionally, the same authors proposed that, during puberty, estrogen plays a critical role in the establishment of sexual behavior by regulating not only sexual motivation but also the ejaculatory process. Therefore, there was damage to the motivational and copulatory aspects of sexual behavior. Previously, our group found that prenatal exposure during the embryogenic period disrupted male sexual behavior (Salvatori et al., 2004). These effects were attributable to the endocrine disrupting-like properties of this metal.

The present results also showed that postnatal testosterone supplementation reversed or attenuated the deleterious effects of perinatal cadmium exposure on the appetitive and consummatory parameters of sexual behavior.

The increases in the latency to the first mount and number of intromissions induced by perinatal cadmium treatment were reversed or attenuated by postnatal testosterone treatment. The latency to ejaculation was not affected by the lower cadmium dose but was increased by the higher dose. In the latter case, postnatal testosterone administration did not reverse the effect. Although both cadmium doses did not alter the postejaculatory latencies, testosterone treatment reduced this sexual parameter. The parameters linked to male sexual behavior were also influenced by postnatal hormone treatment. Thus, the increases in the number of intromissions and total number of mounts induced by the higher cadmium dose were attenuated. Moreover, the reduced number of ejaculations observed after both cadmium doses were completely reversed. Although the effects of androgens, particularly testosterone, on male sexual behavior are indirect (i.e., after aromatization to estrogen), the present data showed that postnatal testosterone supplementation is critical in the prevention of the endocrine-disrupting effect of cadmium on male sexual behavior.
The absolute weights of the body, testes, epididymis, seminal vesicle, and ventral prostate were also evaluated. Compared with the control group, $20 \mathrm{mg} \mathrm{kg}^{-1}$ cadmium decreased the absolute weights of the body, testes, epididymis, and seminal vesicle. Cadmium (10 $\left.\mathrm{mg} \mathrm{kg}^{-1}\right)$ also reduced the weight of the epidydimis.

We previously observed that in infancy, the weight gain between birth and weaning was reduced by perinatal exposure to 10 and $20 \mathrm{mg} \mathrm{kg}^{-1}$ cadmium (Couto-Moraes et al., 2010). Testosterone did not reverse this effect. In adults, this effect persisted only with the higher dose, suggesting that during development this damage was attenuated in rats exposed to $10 \mathrm{mg} \mathrm{kg}^{-1}$. During this age, testosterone supplementation did not reverse this effect.

Perinatal exposure to the higher cadmium dose produced severe toxicity in reproductive organs, reflected by the decreased weights of the testes, epidydimis, and seminal vesicle. Cadmium accumulates in reproductive organs, leading to damage (Al-Azemi et al., 2010; Li et al., 2010; Mendiola et al., 2011).

Cadmium-induced testicular dysfunction is initially mediated by its effects on the occludin/ZO-1/focal adhesion kinase (FAK) complex at the blood-testis barrier [BTB], causing a redistribution of proteins at the Sertoli-Sertoli cell interface. This leads to BTB disruption. The damaging effects of this toxicant on testicular function are mediated by downstream mitogen-activated protein kinases (MAPK) which, in turn, perturb actin bundling and accelerate actinbranching activity, causing a disruption of Sertoli cell tight junction (TJ)-barrier function at the BTB and perturbing spermatid adhesion at the apical ectoplasmic specialization (apical ES), a testis-specific anchoring junction type, which leads to the premature release of germ cells from the testis (for review, see Cheng et al., 2011).

The epidydimis and seminal vesicle were also affected by perinatal exposure to cadmium. Sperm maturation occurs in the epididymis. This process permits the progressive motility, survival, and fertilization success of spermatozoa (Hinton, Meadowcroft, \& Wardle, 1995).

Zenick, Blackburn, Hope, Oudiz, \& Goeden (1984) showed that toxic agents can affect spermatozoa maturation, function, and survival. Calcium can act directly on male gametes or indirectly by compromising epididymal function. In the present study, the decreased weight indicated organ damage. This suggests interference with fertility, which has been reported by several studies. The same facts could explain the reduction of seminal vesicle weight. However, lesions at the microscopic level were not confirmed by histological examination. Several studies showed that cadmium treatment in adult rodents induced histological changes in all of the organs collected in the present study, including the ventral prostate (Arriazu, Pozuelo, Martin, Rodriguez, \& Santamaria, 2005) and testes (Hew, Heath, Jiwa, \& Welsh, 1993; Yu, Hsiao, Yang, Lin, \& Chen, 1997; Zhou et al., 1999). Some testicular alterations caused by cadmium can be observed only using $0.1 \%$ (Liao et al., 2006) or $1 \mathrm{mg} / \mathrm{kg}$ daily for 4 weeks (Haffor \& Abou-Tarboush, 2004). Cadmium- 
induced histological changes in other organs can be consistently observed using specific techniques.

Perinatal or neonatal exposure to some endocrine disruptors impacts testicular weight and steroidogenesis only during infancy, but spermatogenesis can be completely restored during puberty (Kuwada et al., 2002). The lack of differences found in the histology of the testes may be explained by this fact.

Testosterone is the most important and sensitive hormone in the male reproductive system, and the overall evaluation of androgen levels was accomplished by measuring this hormone. No difference was found in serum testosterone levels. Serum testosterone levels, together with the weight measurements and histological evaluation of the reproductive organs, permitted the establishment of morphofunctional correlations and indirect evaluation of the integrity of the hypothalamichypophysis-testes axis, aiding with the evaluation of the toxic effects of one agent (i.e., cadmium) on the male reproductive system.

Altogether, these results indicate that perinatal maternal exposure to cadmium under the present conditions altered sexual parameters in male rat offspring. The results may be explained by alterations in the masculinization of the hypothalamus. Thus, we suggest that the damage to cerebral sexual differentiation was caused by cadmium, reflected by its actions as an endocrine disruptor and supported by the changes discretely observed from early life (i.e., during sexual development) to adulthood (i.e., sexual behavior). Additionally, testosterone administration immediately after birth was able to reverse some of the crucial parameters that are more directly related to the androgenic system.

\section{Acknowledgments}

This research was part of the Master's thesis of Renato Couto-Moraes presented to the Departamento de Farmacologia, Instituto de Ciências Biomédicas, Universidadede SãoPauloand wassupported by fellowships from the Fundação de Amparo à Pesquisa do Estado de São Paulo (grant no. 03/10114-1) to Renato Couto-Moraes and Conselho Nacional de Desenvolvimento Científico e Tecnológico (Conselho Nacional de Desenvolvimento Científico e Tecnológico ([CNPq] grant 301739/2007-2) and Paulista University (grant 7-02-747/2010) to Maria Martha Bernardi and Luciano Freitas Felício. Special thanks are due to the School of Veterinary Medicine (FMVZ-USP) and Brazilian Society of Pharmacology and Experimental Therapeutics (SBFTE).

\section{References}

Agmo, A. (1997). Male rat sexual behavior. Brain Research Brain Research Protocols, 1(2), 203-209.

Agmo, A. (1999). Sexual motivation--an inquiry into events determining the occurrence of sexual behavior. Behavioural Brain Research, 105(1), 129-150.

Al-Azemi, M., Omu, F. E., Kehinde, E. O., Anim, J. T., Oriowo, M. A., \& Omu, A. E. (2010). Lithium protects against toxic effects of cadmium in the rat testes. Journal of Assisted Reproduction and Genetics, 27(8), 469-476.
Arriazu, R., Pozuelo, J. M., Martin, R., Rodriguez, R., \& Santamaria, L. (2005). Quantitative and immunohistochemical evaluation of PCNA, androgen receptors, apoptosis, and glutathione-Stransferase $\mathrm{P} 1$ on preneoplastic changes induced by cadmium and zinc chloride in the rat ventral prostate. Prostate, 63(4), 347-357.

Balthazart, J., \& Ball, G. F. (2007). Topography in the preoptic region: differential regulation of appetitive and consummatory male sexual behaviors. Frontiers in Neuroendocrinology, 28(4), 161-178.

Cheng, C. Y., Wong, E. W., Lie, P. P., Li, M. W., Su, L., Siu, E. R., ... Mruk, D. D. (2011). Environmental toxicants and male reproductive function. Spermatogenesis, 1(1), 2-13.

Corbier, P., Kerdelhue, B., Picon, R., \& Roffi, J. (1978). Changes in testicular weight and serum gonadotropin and testosterone levels before, during, and after birth in the perinatal rat. Endocrinology, 103(6), 1985-1991.

Couto-Moraes, R., Felicio, L. F., \& Bernardi, M. M. (2010). Postpartum testosterone administration does not reverse the effects of perinatal exposure to cadmium on rat offspring development. Journal of Applied Toxicology, 30(3), 233-241.

Felicio, L. F., Palermo-Neto, J., \& Nasello, A. G. (1989). Perinatal bromopride treatment: effects on sexual behavior of male and female rats. Behavioral and Neural Biology 52(2), 145-151.

Freeman, L. M., \& Rissman, E. F. (1996). Neural aromatization and the control of sexual behavior. Trends in Endocrinology and Metabolism 7(9), 334-338.

Gerardin, D. C., Bernardi, M. M., Moreira, E. G., \& Pereira, O. C. (2006). Neuroendocrine and reproductive aspects of adult male rats exposed neonatally to an antiestrogen. Pharmacology Biochemistry and Behavior, 83(4), 618-623.

Grattan, D. R., \& Selmanoff, M. (1994). Castration-induced decrease in the activity of medial preoptic and tuberoinfundibular GABAergic neurons is prevented by testosterone. Neuroendocrinology, 60(2), 141-149.

Haffor, A. S., \& Abou-Tarboush, F. M. (2004). Testicular cellular toxicity of cadmium: transmission electron microscopy examination. Journal of Environmental Biology 25(3), 251-258.

Hew, K. W., Heath, G. L., Jiwa, A. H., \& Welsh, M. J. (1993). Cadmium in vivo causes disruption of tight junction-associated microfilaments in rat Sertoli cells. Biology of Reproduction 49(4), 840-849.

Hinton, R., Meadowcroft, J., \& Wardle, P. (1995). Psychological distress and sub fertility. Journal of the Royal Society of Medicine, 88(4), 237-238.

Iavicoli, I., Fontana, L., \& Bergamaschi, A. (2009). The effects of metals as endocrine disruptors (review). Journal of Toxicology and Environmental Health Part B Critical Reviews, 12(3), 206-223.

Jacobson, C. D., \& Gorski, R. A. (1981). Neurogenesis of the sexually dimorphic nucleus of the preoptic area in the rat. The Journal of Comparative Neurology, 196(3), 519-529.

Kawai, M., Swan, K. F., Green, A. E., Edwards, D. E., Anderson, M. B., \& Henson, M. C. (2002). Placental endocrine disruption induced by cadmium: effects on P450 cholesterol side-chain cleavage and 3beta-hydroxysteroid dehydrogenase enzymes in cultured human trophoblasts. Biology of Reproduction 67(1), 178-183.

Kuwada, M., Kawashima, R., Nakamura, K., Kojima, H., Hasumi, H., Maki, J., \& Sugano, S. (2002). Neonatal exposure to endocrine disruptors suppresses juvenile testis weight and steroidogenesis but spermatogenesis is considerably restored during puberty (comparative study). Biochemical and Biophysical Research Communications, 295(1), 193-197.

Lafuente, A., \& Esquifino, A. I. (1998a). Cadmium does not inhibit pulsatile prolactin secretion through TRH. Biometals, 11(3), 235-241.

Lafuente, A., Gonzalez-Carracedo, A., Cabaleiro, T., Romero, A., \& Esquifino, A. I. (2005b). Toxic effects of cadmium on GABA and taurine content in different brain areas of adult male rats. Journal of Physiology and Biochemistry, 61(3), 439-446.

Lafuente, A., Gonzalez-Carracedo, A., Romero, A., Cabaleiro, T., \& Esquifino, A. I. (2005a). Toxic effects of cadmium on the regulatory mechanism of dopamine and serotonin on prolactin secretion in adult male rats. Toxicology Letters, 155(1), 87-96.

Lephart, E. D. (1996). A review of brain aromatase cytochrome P450 (review). Brain Res Brain Res Rev, 22(1), 1-26.

Li, J. L., Gao, R., Li, S., Wang, J. T., Tang, Z. X., \& Xu, S. W. (2010). Testicular toxicity induced by dietary cadmium in cocks and ameliorative effect by selenium. Biometals, 23(4), 695-705.

Liao, X., Terada, N., Ohno, N., Li, Z., Fujii, Y., Baba, T., et al. (2006).

Immunohistochemical study of serum albumin in normal and cadmium-treated mouse testis organs by "in vivo cryotechnique". Histology and Histopathology, 21(1), 35-40. 
Lovick, T. A. (2012). Estrous cycle and stress: Influence of progesterone on the female brain. Brazilian Journal of Medical and Biological Research, 45(4), 314-320.

MacLusky, N. J., \& Naftolin, F. (1981). Sexual differentiation of the central nervous system. Science, 211(4488), 1294-1302.

Martin, M. B., Voeller, H. J., Gelmann, E. P., Lu, J., Stoica, E. G., Hebert, E. J., \& Reiter, R (2002). Role of cadmium in the regulation of AR gene expression and activity. Endocrinology, 143(1), 263-275.

Meisel, R. L., \& Joppa, M. A. (1994). Conditioned place preference in female hamsters following aggressive or sexual encounters. Physiology and Behavior, 56(5), 1115-1118.

Mendiola, J., Moreno, J. M., Roca, M., Vergara-Juarez, N., MartinezGarcia, M. J., Garcia-Sanchez, A., ... Torres-Cantero, A. M. (2011). Relationships between heavy metal concentrations in three different body fluids and male reproductive parameters: a pilot study. Environmental Health, 10(1), 6.

Murthy, R. C., Saxena, D. K., Lal, B., \& Chandra, S. V. (1989). Chronic cadmium-ethanol administration alters metal distribution and some biochemicals in rat brain. Biochemistry International, 19(1), 135-143.

Piasek, M., Laskey, J. W., Kostial, K., \& Blanusa, M. (2002). Assessment of steroid disruption using cultures of whole ovary and/or placenta in rat and in human placental tissue. International Archives of Occupational and Environmental Health, 75(suppl), S36-44.

Piffer, R. C., \& Pereira, O. C. (2004). Reproductive aspects in female rats exposed prenatally to hydrocortisone. Comparative Biochemistry and Physiology C Toxicology and Pharmacology 139(1-3), 11-16.

Pillai, A., \& Gupta, S. (2005). Effect of gestational and lactational exposure to lead and/or cadmium on reproductive performance and hepatic oestradiol metabolising enzymes. Toxicology Letters, 155(1), 179-186.

Pollock, B., \& Machin, K. L. (2008). Effects of cadmium, mercury, and selenium on reproductive indices in male lesser scaup (Aythya affinis) in the western Boreal forest. Archives of Environmental Contamination and Toxicology, 54(4), 730-739.
Roselli, C. E., \& Klosterman, S. A. (1998). Sexual differentiation of aromatase activity in the rat brain: effects of perinatal steroid exposure. Endocrinology, 139(7), 3193-3201.

Salvatori, F., Talassi, C. B., Salzgeber, S. A., Spinosa, H. S., \& Bernardi, M. M. (2004). Embryotoxic and long-term effects of cadmium exposure during embryogenesis in rats. Neurotoxicology and Teratology, 26(5), 673-680.

Sonnenschein, C., \& Soto, A. M. (1998). An updated review of environmental estrogen and androgen mimics and antagonists. Journal of Steroid Biochemistry and Molecular Biology, 65(1-6), 143-150.

Stoica, A., Katzenellenbogen, B. S., \& Martin, M. B. (2000). Activation of estrogen receptor-alpha by the heavy metal cadmium. Molecular Endocrinology, 14(4), 545-553.

Takiguchi, M., \& Yoshihara, S. (2006). New aspects of cadmium as endocrine disruptor. Environmental Science, 13(2), 107-116.

Temple, J. L., Scordalakes, E. M., Bodo, C., Gustafsson, J. A., \& Rissman, E. F. (2003). Lack of functional estrogen receptor beta gene disrupts pubertal male sexual behavior. Hormones and Behavior, 44(5), 427-434.

Ward, I. L., \& Weisz, J. (1984). Differential effects of maternal stress on circulating levels of corticosterone, progesterone, and testosterone in male and female rat fetuses and their mothers. Endocrinology, 114(5), 1635-1644.

Yu, L. C., Hsiao, Y. L., Yang, Y. H., Lin, M., \& Chen, Y. H. (1997). The genomic structure of a mouse seminal vesicle autoantigen. Biochemical and Biophysical Research Communications, 231(1), 106-110.

Zenick, H., Blackburn, K., Hope, E., Oudiz, D., \& Goeden, H. (1984) Evaluating male reproductive toxicity in rodents: a new animal model. Teratogenesis Carcinogenesis Mutagenesis, 4(1), 109-128.

Zhang, W., Pang, F., Huang, Y., Yan, P., \& Lin, W. (2008). Cadmium exerts toxic effects on ovarian steroid hormone release in rats. Toxicology Letters, 182(1-3), 18-23.

Zhou, T., Zhou, G., Song, W., Eguchi, N., Lu, W., Lundin, E., et al. (1999). Cadmium-induced apoptosis and changes in expression of p53, c-jun and MT-I genes in testes and ventral prostate of rats. Toxicology, 142(1), 1-13. 
